\title{
Reply to: The 'Seal' of Sir Shackleton
}

\author{
Bruce A. Griffin ${ }^{1}$
}

Published online: 13 August 2020

(c) Springer-Verlag GmbH Germany, part of Springer Nature 2020

To suggest that diet played a causative role in the plight of the two parties of men is an interesting possibility and emotive idea. However, a closer examination of the circumstances of each party, reveals extreme differences in environmental conditions, levels of exposure to cold, physical activity, energy intake and expenditure. While these differences will have produced significant and confounding impacts on the physical and mental health of the men, at specific, critical times, the diets of the two parties were actually very similar.

After his ship, 'The Endurance', was crushed by ice, Shackleton's party spent months drifting on an ice floe. Apart from hunting for food (seals, penguins and occasional fish), his men were largely sedentary and passed the time of day by reading books in their tents. In complete contrast, Captain Mackintosh's men marched for 1561 miles in the worst weather conditions imaginable, eating what became no more than a starvation diet. As a result, the men suffered physical exhaustion, frostbite and scurvy, which eventually claimed the life of one man. The lives of two other men, including Captain Mackintosh, would be lost after a period of recuperation at a base camp 'Hut Point'. During this time,
Mackintosh's men ate a diet replete with seal meat and dried vegetables. This diet was similar to that of Shackleton's men after they had exhausted their supplies of flour and sugar. Only after consuming this diet for over 8 weeks, and recovering from exhaustion and scurvy, did Mackintosh make the fatal mistake of attempting to reach the next camp with a fellow explorer. This decision went against the advice of the other members of the party and cost the two men their lives [1].

Emerging evidence for the potential benefits of a ketogenic diet on mental disorders is encouraging. Unfortunately, the extreme differences in the circumstances of the two parties of Shackleton's last Antarctic expedition, make it difficult to establish if a ketogenic diet played a causative role in their fate.

\section{Reference}

1. South (2019) The illustrated story of Shackleton's last expedition. Voyageur Press. Beverly. (ISBN:978-0-7603-6482-6)

This reply refers to the following letter: https://doi.org/10.1007/ s00394-020-02349-3.

An introduction to the letter and reply can be read here: https://doi. org/10.1007/s00394-020-02348-4.

Bruce A. Griffin

b.griffin@surrey.ac.uk

1 Department of Nutritional Sciences, Faculty of Health and Medical Sciences, University of Surrey, Surrey, UK 